\title{
I ntegrating a Virtual Community of Practice (VCoP) into graduate psychiatric nursing curriculum
}

\author{
J illian M. J evack ${ }^{1}$, Kathleen R. Tusaie ${ }^{2}$, J effrey S. Jones ${ }^{2}$, Patricia J. Purcell ${ }^{2}$, Marlene S. Huff ${ }^{2}$ \\ 1. College of Health Professions, The University of Akron, Akron, Ohio, USA. 2. School of Nursing, College of Health \\ Professions, The University of Akron, Akron, Ohio, USA.
}

Correspondence: Jillian M. J evack. Address: College of Health Professions, The University of Akron, Akron, Ohio, USA. Email: jillian.jevack@gmail.com

Received: May 10, 2014

DOI : $10.5430 /$ jnep.v4n9p100
Accepted: June 15, $2014 \quad$ Online Published: July 20, 2014

URL: http://dx.doi.org/10.5430/jnep.v4n9p100

\section{Abstract}

Introduction: The 2003 Institute of Medicine report, Health Profession Education: A Bridge to Quality, establishes the need for increased informatics literacy in all health care disciplines. The focus upon computerized health care records, data management, e-prescribing, and telehealth exists, but minimal literature is available addressing the use of Virtual Communities of Practice (VCoP) in education. The theory of connectivism provides the framework for this project, focusing on student autonomy, connectedness, diversity, and openness.

Method: A pilot to explore feasibility and initial impressions of the inclusion of a VCoP into the last 2 semesters of a graduate Psychiatric Nursing curriculum was conducted. Development of the assignment including creation of a selfdirected online tutorial and grading rubric was completed. Initial evaluation of feasibility as well as reactions was assessed using student grades on the rubric, impressions of faculty, and themes from a student focus group. The purpose of involvement in a VCoP provides professional interaction and incentive toward developing a scholarly paper.

Results: Initial reaction was overall negative; however, as length of time participating in the VCoP expanded, students became more proficient and reactions trended more positive with all students predicting they would continue to participate in the VCoP after graduation. Students also recommended the continued use of the VCoP for future students.

Conclusion: The use of a Virtual Community of Practice as part of a graduate Psychiatric Nursing Curriculum is feasible and can be implemented in future classes. Modification of the grading rubric is indicated. Longitudinal follow up will continue to provide information regarding use after graduation. Further research is needed to evaluate effects of participation in a VCoP.

\section{Key words}

Virtual, Communities of practice, Education, Connectivism, Graduate Psychiatric nursing curriculum

\section{Introduction}

Following the 2003 Institute of Medicine report Health Profession Education: A Bridge to Quality, there was an explosion of informatics literacy into the graduate nursing curriculum. Computerized healthcare records, e-prescribing, data 
management and telehealth were included into curriculums, but there was minimal attention to including Virtual Communities of Practice (VCoP).

Participation in a VCoP holds the potential to expand networking and knowledge beyond the local area and textbooks. Adding a requirement for graduate psychiatric nursing students to participate in a VCoP for psychiatric nurses not only maintains the core concept of interpersonal relationships but would also move the curriculum into the digital age and would be consistent with the new learning theory of connectivism. The theory is based upon the premise that knowledge exists in the world rather than in the head of an individual. Four key principles of connectivism include autonomy, connectedness, diversity, and openness ${ }^{[1]}$. These principles are present within VCoP, which afford the potential for synchronous as well as asynchronous communication and collaborative pedagogical models.

\subsection{Definition of VCoP}

Communities of Practice are defined as "groups of people who share a concern, a set of problems, or a passion about a topic, and who deepen their knowledge and expertise in this area by interacting on an ongoing basis" ${ }^{[2]}$.

The structural model of a "Community of Practice" includes the domain, the community, and the practice. These elements form a social model through which knowledge is stewarded ${ }^{[2]}$.

The domain of the VCoP for this study is psychiatric mental health nursing. The community includes advanced practice nursing students, faculty, and various clinicians. The practice is the specific knowledge about caring for a person with a mental illness and promoting mental health while transforming oneself from a generalist nurse role towards an advanced practice nurse role.

The large amount of available information and the use of social networking are advantageous to learning. Available time and financial constraints of meeting in person have negatively impacted role modeling of the interpersonal process, yet there is more opportunity to participate and to exchange information digitally. Furthermore, if there is formal identification of a virtual community that is supported by the institution, rapid and easy sharing of knowledge and practices is facilitated ${ }^{[3]}$.

Etienne Wenger ${ }^{[4]}$ described further advantages of VCoP which include building knowledge competencies, improving efficiency, and providing for sharing of knowledge and ideas. A symbiotic relationship emerges where each person learns from the other, often through discussions of realistic problems, real life, and complex situations. In a teaching virtual community of practice, the teacher role is to facilitate the learning process, offer knowledge, and guide problem solving. Through the social processes of interacting in a virtual community, knowledge and learning is created and disseminated. The group becomes connected as they develop trust and openness.

The definition of a VCoP for this study is a group of people who are building skill and knowledge of advanced practice psychiatric mental health nursing, using technology to support learning in a formal institutional network. Related assumptions include that each member will assume responsibility for participating in the group sharing their expertise and retrieved knowledge to solve complex problems, will have the necessary technology to participate efficiently, and that the teacher will facilitate the process of learning and problem solving.

\subsection{Literature review}

Rapid development of the internet and social media programs in the late 1900's led to learning platforms and online class delivery systems ${ }^{[5]}$. Providing students the opportunity to collaborate and share ideas with other students became reality. There is a wealth of information that can be accessed via the internet; finding a way to incorporate it into the classroom is a challenge. Thus, supporting a VCoP in health care curricula became a topic of interest. 
The origins of communities of practice can be traced back to the middle ages with groups of craftsmen. However, the $\mathrm{VCoP}$ is more recent and originated in the world of business during the global and technological advances in the $1980 \mathrm{~s}^{[2]}$. The expansion to health care providers is more recent but is rapidly growing ${ }^{[6-9]}$. More specifically, the internet has been instrumental in bringing Psychiatric Nurse Practitioners as well as students together. A recent Google (n.d.) search produced 1,380,000 links using the search terms "psychiatric + nurse practitioner + listserve.” Increased broadband availability as well as increased techniques for interactivity has made the current and future use of online communities a reality ${ }^{[10]}$.

VCoP in healthcare are promoted as computer mediated communication to generate and share knowledge and improve performance in addition to promoting a sense of connectedness. However, VCoPs vary greatly in their formation and operation. Therefore, researchers have started to examine how and why VCoP are organized and if there has been an improvement in performance. One of the earliest peer reviewed, empirical studies of VCoP in healthcare was in 1999 with the majority having been published after 2007. The countries of origin included United Kingdom, Canada, United States, Australia, and Denmark ${ }^{[5,11]}$.

Although much diversity in VCoP has been identified by Ranmuthugala and colleagues ${ }^{[11]}$, several themes in research studies have been identified. First, there was an intention to facilitate learning, share information and improve practice. Second the most common methods of communication included e-mail and the internet, but there was controversy among the studies regarding the need for some face-to-face time to maintain interest and involvement. Finally, improvements in practice related to the use of VCoP included gaining competencies, breaking down professional and geographical barriers, sharing information, decreasing professional isolation, facilitating development of new policies and procedures and decreasing lag time between research and practice ${ }^{[12-14]}$.

The stages of group development may contribute to the effectiveness of the VCoP. As in any group, a VCoP goes through developmental stages, from coalescence into more mature stages including a stewardship ${ }^{[15]}$. Some VCoP may quickly develop relationships and progress forward, while others may not move beyond the early stages. Some factors that may contribute to the unsuccessful VCoP include lack of time to participate, lack of technical knowledge, lack of leaders, more observation and lurking than active involvement.

\subsection{VCoP and education}

The use of technology in academic and clinical teaching is growing as educators become more of a "guide on the side" rather than "a sage on the stage" ${ }^{[16]}$. This approach to teaching puts more responsibility on students, but also increases the need for faculty to be cyberliterate. Students need not only to use web-based resources during their classes but also to be aware of the technological possibilities for their future practices.

Using a horizontal rather than a vertical relationship between educator and students can enhance participation and collaboration among the group. Wenger ${ }^{[2]}$ suggests that most learning for health care workers occurs as situated learning, where new workers develop skills by interacting in the workplace with colleagues possessing more knowledge and experience. However, the crowded Nurse Practitioner curriculum and limited availability of clinical learning sites are growing barriers to Psychiatric Nurse Practitioners education. However, the movement of a nurse from novice to expert requires the integration of clinical knowledge and socialization into the profession ${ }^{[17]}$. Thus, the VCoP has the potential to offer rich learning opportunities with information that may not be published and available in an academic environment.

Because there is a gap in the literature addressing the use of VCoP in Psychiatric Nurse Practitioner programs, this study explored the feasibility of integrating participation in the American Psychiatric Nurses Association VCoP as part of the curriculum. The strengths as well as weaknesses of this integration were explored from the student and faculty perspective. An additional aspect to this study included evaluation of students' ability to participate at expected levels of quality and quantity. 


\section{Method}

\subsection{Design}

This descriptive, longitudinal feasibility study was completed in two phases - first, development of an online tutorial for the VCoP, a grading rubric for student participation, and instructions within the course syllabus and second, implementation and evaluation.

\subsection{Sample}

A convenience sample of graduate students enrolled in the last year of the psychiatric nurse practitioner track at a large mid-eastern United States public university was used. After an explanation of the study, the six students signed consents to participate. The university IRB granted an exempt status for the study. The sample included one male and five females. Ages ranged from 24 to 42 with a mean of 36. There were 2 African American students and four Caucasian. Four students were married and all were working as psychiatric nurses for 24 to 40 hours per week.

\subsection{Development of the tutorial, grading rubric, and assignment}

To integrate the VCoP into the curriculum, a team consisting of the instructor, an expert in VCoP, and an instructional designer worked together to develop an assignment that would become part of the course requirements. The assignment required students to participate in the VCoP using the tools including blogs and discussions available on the American Psychiatric Nurses Association (APNA) website, and was described in the syllabus to the students both in the Fall and Spring Semesters.

The team also developed a rubric by which students would be evaluated; this rubric was provided to students in the syllabus along with the assignment description and is shown in Table 1.

Table 1. VCoP Assignment Rubric

\begin{tabular}{|c|c|c|c|c|c|}
\hline Domain Expectation & Exemplary 5 & Above Average 4-3 & $\begin{array}{l}\text { Minimally Acceptable } \\
2-1\end{array}$ & Unacceptable 0 & $\begin{array}{l}\text { Total Possible } \\
\text { Points } 20\end{array}$ \\
\hline $\begin{array}{l}\text { Content } \\
\text { Introduces original topic in } \\
\text { new blog or existing thread } \\
\text { concerning relevant issues to } \\
\text { psychiatric APRN nursing } \\
\text { practice as well as actively } \\
\text { participates in a variety of } \\
\text { communities' discussion. } \\
\text { (i.e. general practice, student, } \\
\text { Ohio chapter, APRN) }\end{array}$ & $\begin{array}{l}\text { Provides one original topic that } \\
\text { is complex and multifaceted } \\
\text { enough to generate multiple } \\
\text { dynamic conversations (multiple } \\
\text { threads) with active responses of } \\
10 \text { or more to the original } \\
\text { posting. Participates in at least } 4 \\
\text { other communities' discussions. }\end{array}$ & $\begin{array}{l}\text { Provides one original topic } \\
\text { and actively responds (6-9 } \\
\text { times) throughout the } \\
\text { semester. Participates in at } \\
\text { least } 3 \text { other communities' } \\
\text { discussions. }\end{array}$ & $\begin{array}{l}\text { Provides one original } \\
\text { topic with minimal } \\
\text { interaction (1-5 times) } \\
\text { with respondents } \\
\text { throughout the semester. } \\
\text { Participates in at least } 2 \\
\text { other communities' } \\
\text { discussion. }\end{array}$ & $\begin{array}{l}\text { Does not introduce or } \\
\text { provide any original } \\
\text { idea as blog or thread. } \\
\text { Participates in only } 1 \\
\text { other communities' } \\
\text { discussion. }\end{array}$ & 5 \\
\hline $\begin{array}{l}\text { Communication } \\
\text { Communicates in a } \\
\text { professional manner that } \\
\text { indicates scholarly thought. }\end{array}$ & $\begin{array}{l}\text { Explains all of ideas of topic } \\
\text { clearly, concisely, and } \\
\text { constantly in a logical } \\
\text { progression with effective } \\
\text { supporting evidence that reflects } \\
\text { scholarly thinking. }\end{array}$ & $\begin{array}{l}\text { Explains most of ideas of } \\
\text { topic clearly and concisely } \\
\text { with supporting evidence. }\end{array}$ & $\begin{array}{l}\text { Explains ideas of topic } \\
\text { incompletely and does } \\
\text { not effectively or } \\
\text { consistently use } \\
\text { supporting evidence. }\end{array}$ & $\begin{array}{l}\text { Fails to explain ideas } \\
\text { of topic clearly } \\
\text { (reader is confused), } \\
\text { and does not use any } \\
\text { supporting evidence. }\end{array}$ & 5 \\
\hline $\begin{array}{l}\text { Mechanics } \\
\text { Content is free of distracting } \\
\text { errors in grammar, } \\
\text { punctuation, etc. }\end{array}$ & $\begin{array}{l}\text { Posts content with no errors in } \\
\text { grammar, capitalization, } \\
\text { punctuation, and spelling. }\end{array}$ & $\begin{array}{l}\text { Posts content with few or } \\
\text { minor errors in grammar, } \\
\text { capitalization, punctuation, } \\
\text { and spelling so as not to } \\
\text { distract from readability. }\end{array}$ & $\begin{array}{l}\text { Post content that } \\
\text { contains multiple errors } \\
\text { in grammar, } \\
\text { capitalization, } \\
\text { punctuation, and spelling } \\
\text { that may distract or } \\
\text { impair readability. }\end{array}$ & $\begin{array}{l}\text { Posts content that has } \\
\text { numerous errors in } \\
\text { grammar, } \\
\text { capitalization, } \\
\text { punctuation, and } \\
\text { spelling and is so } \\
\text { distracting that it is } \\
\text { unreadable. }\end{array}$ & 5 \\
\hline $\begin{array}{l}\text { Use of Hyperlinks or } \\
\text { Citations } \\
\text { Provides links to documents, } \\
\text { articles, or websites that } \\
\text { enhance dialogue. }\end{array}$ & $\begin{array}{l}\text { Includes links to websites or } \\
\text { documents that consistently } \\
\text { enhance the information } \\
\text { presented and stimulate } \\
\text { discussion. }\end{array}$ & $\begin{array}{l}\text { Includes links to websites } \\
\text { or documents, but not all } \\
\text { links consistently enhance } \\
\text { the information presented. }\end{array}$ & $\begin{array}{l}\text { Includes links to } \\
\text { websites or documents } \\
\text { but are inappropriate for } \\
\text { furthering discussion. }\end{array}$ & $\begin{array}{l}\text { Does not include any } \\
\text { links. }\end{array}$ & 5 \\
\hline
\end{tabular}


In addition to the assignment description, which explained to students what virtual communities of practice were and why they were being asked to participate in one, and the rubric, which explained how they would be evaluated, students also needed to know how to use the blog and discussion tools required by the assignment. Therefore, a self-paced tutorial was developed and available both semesters. Students were expected to complete this tutorial prior to attempting the assignment and could review it as needed throughout both semesters.

The tutorial established the following learning objectives:

1) Define "virtual communities of practice."

2) Describe the value of participating in virtual communities of practice.

3) Explain what blogs are and how they relate to virtual communities of practice.

4) Explain what discussions are and how they relate to virtual communities of practice.

5) Compare and contrast blogs and discussions.

6) Participate in a virtual community of practice using blogs and discussions.

The tutorial was framed as a series of questions related to these objectives, including:

1) What is a virtual community of practice?

2) Why would someone want to take part in a virtual community of practice?

3) What are the benefits of a virtual community of practice?

4) What does it take to develop and sustain a successful virtual community of practice?

5) What is a blog?

6) What is a discussion?

7) What is the difference between a blog and a discussion?

8) How do I blog?

9) How do I discuss?

Information addressing each of these questions was provided in multiple media formats, including text, video, interactive elements, hyperlinks, narrated demonstrations, printable guides, and images. Perhaps the most critical of these to the students' ability to complete the assignment was the narrated demonstrations and the printable guides that accompanied them. In these demonstrations, students were shown how to navigate the APNA website, including how to view and comment on blog posts, create their own blog posts, view and reply to discussions, and post their own discussions. Thus, students were provided with the technical training needed to complete the assignment.

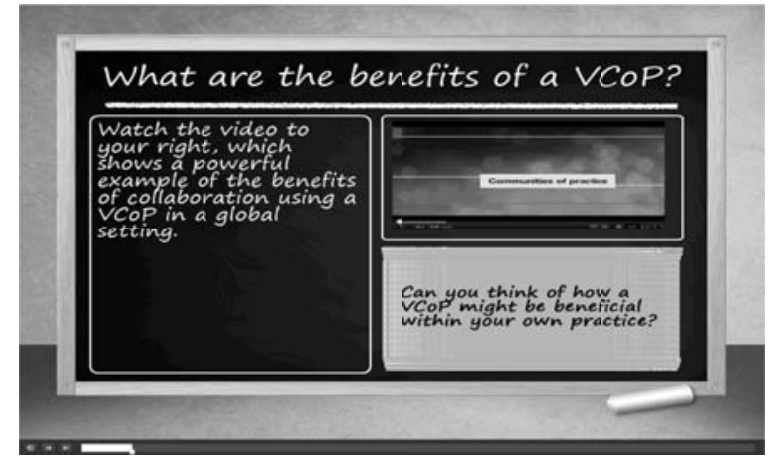

Figure 1. On this screen of the tutorial, students watch a video about the benefits of VCoP



Figure 2. On this screen of the tutorial, students click to reveal additional benefits of VCoP 


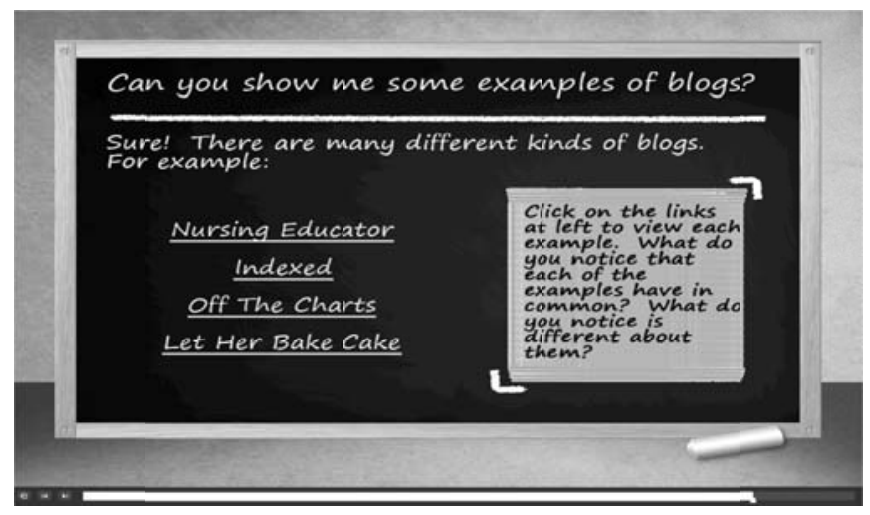

Figure 3. On this screen of the tutorial, students visit examples of blogs

\subsection{I mplementation of the assignment}

The instructor introduced the assignment to the students in the Fall semester and explained that it was a pilot program which included student memberships to the APNA and thus access to the APNA website. Students received the assignment information and rubric in the syllabus and were instructed to begin participating in the VCoP on the APNA website.

The pilot continued in the Spring semester. The Spring semester furthered the concepts introduced in the original assignment as follows:

This semester you will continue a discussion on the American Psychiatric Nurses Association (APNA) website. The goal again is to introduce an original topic in a new discussion concerning relevant practice/clinical issues pertaining to psychiatric APRN nursing practice and connect to other APRN students and practicing APRN's in the global community. This should be a clinical topic that you feel passionate about and/or think is important for the profession. It can be an extension of your VCOP discussion in APRN III and / or related to your scholarly paper or it can be a new idea or concept. The topic should be one that is focused on clinical practice and is complex and multifaceted for dynamic conversation (multiple threads) with active responses of 10 or more by the student.

Students were informed that the instructor would not be commenting on their discussion and blog postings online in order not to stifle the conversation. However, during in-class and informal discussions the instructor would respond to student questions and facilitate participation in the VCoP.

At the conclusion of the second semester the students participated in a focus group about the assignment and were invited to comment on the future utility of VCoP in their own practice. A faculty not teaching the course facilitated the group to encourage open communication and avoid bias.

\subsection{Data analysis/ evaluation}

Thematic analysis and descriptive statistics were used for evaluation. The thematic analysis of the focus group involved transcription, then listing each question with most frequent phrases in the discussion, then dividing comments into positive and negative components. Two individuals not involved in the study completed the analysis independently and then compared findings to identify themes.

The grading rubric scores of the students were analyzed with descriptive statistics and faculty impressions were included as narratives with identified observations. 


\section{Results}

\subsection{Student performance on the assignment}

Grades, as per the grading rubric for the Fall 2012 introduction of the assignment ranged from A (95\%) to F (45\%). Class mean score was C- (72\%). Class mean for each category was as follows: Content 3.5 out of 5, Communication 4.3 out of 5, Mechanics 5 out of 5, and Use of Hyperlinks or Citations 1.6 out of 5.

Grades, as per the grading rubric for the Spring 2013 continuation of the assignment were all (95\%) A. Class score for each category was as follows: Content 4 out of 5 , Communication 5 out of 5, Mechanics 5 out of 5 , and Use of Hyperlinks or Citations 5 out of 5 .

The following are three different examples of posts made by students to the All-Purpose Discussion Forum in response to the assignment.

\section{Subject: PMHNPs \& Psychotherapy}

Posted: October 26, 2012

I am a Family Psychiatric \& Mental Health Nurse Practitioner student who has noticed a trend...I have noticed that PMHNPs seem to be faced with having to negotiate for opportunities to do therapy with their clients. Most institutions seem to strictly assign PMHNPs to med management roles. Has anyone faced the challenge of wanting to do therapy with their clients, while not being permitted this opportunity? Also, has anyone faced this challenge and received permission to start a client case load for therapy? What advice would you give new PMHNPs on this topic? I look forward to hearing from anyone who has thoughts on this topic.

\section{Subject: Are APN specialists going by the wayside?}

Posted: November 7, 2012

I am concerned in today's health care environment the APN specialist may fall out of favor and in its place the APN generalist will be the future. I am a Family Psych APN student getting ready to graduate and have received a lot of education in caring for the mental health needs of children, adolescents and adults. I specialized in mental health and cannot imagine having to take care of medical needs as well. Adult and pediatric assessment/patho were included in my coursework which gives me some working knowledge of the medical problems that my patients face. I want to focus on the mental health needs of my patients and would not want to be spread too thin by having to take on the medical needs as well. Is anyone seeing this in their facilities where generalist APN's are being hired in place of a specialist?

\section{Subject: Have APN's given up their role as therapists?}

Posted: February 9, 2013

Hello...I am a Family Psychiatric Nurse Practitioner student...My cohort is in our last semester prior to graduation and we are discussing the important aspects of negotiating work contracts with potential employers. I love doing therapy with clients. To me, it is the best part of our role. I am fortunate to be able to do a therapy internship at the agency where I am doing clinical this semester. It seems that many people are surprised that Psychiatric Nurse Practitioners are able to do therapy. I had to arrange for the therapy internship through the counseling department of the agency where I am completing my clinical hours. Are any APN's on this discussion doing therapy? I believe it is a part of our role that we should firmly hold on to especially now that the CNS role is being dismantled (which I believe is so unfortunate). Some APN's prefer Med/Som some are more interested in therapy, however no matter which we prefer I believe it is up to all of us to advocate for the continuation of our role as a therapist. What are your thoughts? 
Could those responding to this please post their response to the group instead of using e-mail format? This discussion is part of class assignment and will be followed by my classmates and instructor. Thank you!

\subsection{Students' impressions}

At the conclusion of the semester the students were questioned in a focus group about the assignment. The thematic analysis from the transcript of the final recorded focus group revealed several important insights into the experience. There were overall 20 positive words or themes elicited during the interview and 21 negative words or themes elicited. Sample of positive words used were: reflective, helpful, and good. Sample of negative words used were negative, not much value, and disappointing. In all there were 6 dominating themes expressed. They could be divided as follows:

\section{Positive themes}

Theme 1- The virtual community was an enriching experience.

Theme 2- The virtual community was an educational resource.

Theme 3- The virtual community offered helpful and positive experiences.

\section{Negative themes}

Theme 4- Course requirements inhibited meaningful use of the virtual community.

Theme 5- There was difficulty maintaining discussion threads, especially on topics of student interest.

Theme 6- There was difficulty navigating the site.

Interestingly, while there were almost as many positive words as negative, overall the taped group conversation trended negative with the same two students dominating the conversation and influencing this trend. The student that had positive opinion of the experience spoke less frequently. Even though the themes trended negative toward the end the entire student group seemed open to using or attempting to use VCoP after they had transitioned to the APRN role. This change in the trend seemed to emerge from awareness that while in school they (students) are immersed in an academic environment with many resources for learning (faculty, curricula, peers) but once graduated the landscape changes and there may be a shift in what's readily available to them in their practice. Perhaps this is best reflected in one student's final comment of "You're right. You do have a lot more resources now. And then when we're out there it will be different. So maybe I will utilize this more." Another positive opinion by the group was that the VCoP should be used for future classes with modifications in the grading rubric.

\subsection{Instructor's impressions}

The six students approached the first phase of the assignment during its introduction in the Fall semester of 2012 with initial interest. As the semester unfolded a general attitude of frustration seemed to emerge, particularly at not being able to generate a topic that led to dynamic discussion. The students' topics up to that point overall tended to be outgrowths of class material. Only one student posted a discussion that was not somehow tied to current course content.

Several discussions in class ensued about relevant topics that might change this dynamic. A series of small group/seminar type class activities were employed to stimulate thinking about how to engage with others on a global level. In particular, the interpersonal aspects of group therapy were employed. For this semester, the students were learning group therapy concepts as proposed by Irving Yalom. As an object lesson, the class was asked to envision the discussion group from a group therapy perspective. Insight into their participation up to that point consisted mainly of early development of socialization techniques and imparting of information. Emphasis that movement toward a more rewarding connection with the on-line group may not occur until they could find themes that spoke to Yalom's concept of universality and had a broader appeal ${ }^{[18]}$. 
Enthusiasm for the assignment significantly waned by the end of the Fall semester with only one student reporting that they still enjoyed the assignment and was continuing the discussions well past the end date. The rubric scores correlated with the students' attitude around the assignment. The highest score was achieved in the mechanics category indicating that the posts were free from spelling and grammatical errors. The second highest scores appeared in the communication category, reflecting that overall when they did post something it was coherent and professional. The third highest scores went to the area of content. This was an area of general struggle for them as they floundered at times attempting to find a voice on the discussion board regarding relevant global issues that would flourish. Use of hyperlinks and citations was the lowest scored category and was the result of three of the six students saying that simply didn't know this was an expectation as they hadn't reviewed the grading rubric beyond the first day of class and a fourth student saying she didn't know how to insert a citation or hyperlink. The remaining two students had no problems completing the expectations of this category.

Limitations for this first phase of the project seemed to be the inability of the students to see this assignment as anything beyond just that. Discussions around the opportunities to connect to other psych APRN students tended to continue to gravitate toward their seeing this as an opportunity to "commiserate" with other APRN peers regarding being in school, the state of the art, etc. They had seemingly yet to operationalize this assignment as a possible skill/tool with any utility for future application.

The following phase of the assignment was modified in an effort to marry the clinical/didactic content conceptually for the student and the VCoP grade was now part of their clinical grade. In general the Spring phase of this project found the students generally more accepting of the assignment, particularly as the emphasis was now placed on their VCoP conversations providing momentum toward a scholarly paper. Most of their anxiety transferred now to the writing of a scholarly paper and the VCoP assignment seemed more comfortably integrated into their overall routine of managing assignments. It may be that the experience and perceived benefit of such an assignment was now becoming operationalized. The instructor continued the policy of not participating in the VCoP discussions but did monitor the postings for activity and content.

Subsequently, the grades for this phase of the project were significantly higher in this format. All five students (one student had withdrawn from the program) were able to achieve 19/20 points. Each of the students this time actively utilized hyperlinks and / or posted articles to support their discussions. The one area preventing full attainment of the points was the inability to create a discussion thread that generated 10 responses. In retrospect the expectation of achieving 10 responses in this category may have been unrealistically high for the novice student and the nature of this assignment.

\section{Discussion}

\section{Feasibility}

The purpose of this study was to explore the feasibility of integrating participation in the American Psychiatric Nurses Association VCoP as part of the curriculum. All students were able to participate in the VCoP and meet rubric criteria. Initially students had some technical difficulties as well as anxiety and negative attitudes, but by the second semester this waned and there was more interest as well as higher grades for participation.

In fact, during the 2 semesters, two students were identified as having the highest number of comments within the VCoP for that month. Another interesting development was the ability of the students to create national attention. An editorial by Karen Stein ${ }^{[19]}$, A Pressing Question: Is There a Place for Psychotherapy in PMHNP Practice?, referred to some of the postings by our students and the subsequent discussions as antecedents for its appearance.

Therefore, this initial integration of a VCoP into the curriculum seems to be quite feasible. 
Comments from students indicate they do see the value for after they graduate even though they might not see the value as a student. This is consistent with the concept of autonomy in the theory of connectivism. When the students were participating in the VCoP as students it was because this activity was required. Although they all participated, this action of making comments and starting threads of topics, there was only minimal sense of connectedness with others in the VCoP except for the other students in their class. This sense of association or sense of intimacy and fellowship may have been lacking for several reasons. First, many of the participants were experienced Advanced Practice Nurses and some of the students expressed feelings of inadequacy. This may be decreased after graduating, passing the certification examination and practicing for at least a year. It will be interesting to reevaluate sense of connectedness in a year to see if they were able to transcend action, not only to continue to respond but to have a sense of responsibility to the community in general. Another possible reason is the short time students participated. As time passes and those students who continue to participate may have more of a sense of connectedness as they are distanced from the academic group and the VCoP evolves. Action as well as a sense of connectedness is needed for a true community as well as a VCoP to be effective.

Future directions include reiterating the assignment in subsequent semesters with adjustments made based on the feedback from this initial experience and quantitatively evaluate students' sense of connectedness and level of resilience for triangulation of findings. It is only through longitudinal application and analysis that the utility of the VCoP experience itself can be more clearly understood.

\section{References}

[1] Siemens, G. Connectivism: A learning theory for the digital age. International Journal of Instructional Technology and Distance Learning. 2005; 2(1): 3-10.

[2] Wenger, E., McDermott, R. A., \& Snyder, W. Cultivating Communities of Practice: A Guide to Managing Knowledge. Boston, MA: Harvard Business School Press; 2002.

[3] Office of Educational Access and Success (OEAS), University System of Georgia. Development of Virtual Communities of Practice to Support Programmatic Efforts within University Systems. 2012; 1-17. Available from: http://www.usg.edu/educational_access/documents/OEAS_12-01_Communities_of_Practice.pdf 6/24/14.

[4] Wenger, E. Communities of Practice: Learning, Meaning and Identity. Cambridge, UK: Cambridge University Press; 1998. http://dx.doi.org/10.1017/CBO9780511803932

[5] Barnett, S., Jones, S.C., Bennett, S., Inverson, D., \& Bonney, A. General practice training and virtual communities of practice - A review of the literature. BMC Family Practice. 2012; 13(87): 1471-2296.

[6] Brooks, F. \& Scott, P. Exploring knowledge work and leadership in online midwifery communication. Nursing and Healthcare Management. 2006; 510-520. PMid:16866846

[7] Cook-Craig, P.G. \& Sabah, Y. The role of virtual communities of practice in supporting collaborative learning among social workers. British Journal of Social Work. 2009; 39: 725-739. http://dx.doi.org/10.1093/bjsw/bcp048

[8] Curran, C.R., Elfrink, V., \& Mays, B. Building a virtual community for nursing education: The town of Mirror Lake. Journal of Nursing Education. 2009; 48: 30-35. PMid:19227753 http://dx.doi.org/10.3928/01484834-20090101-03

[9] Gammelgaard, J. Knowledge retrieval through virtual communities of practice. Behavioral Information Technology. 2010; 29(4): 349-362. http://dx.doi.org/10.1080/01449290903548406

[10] Sawyer, R.K. Social emergence: Societies as complex systems. Cambridge University Press; 2005. http://dx.doi.org/10.1017/CBO9780511734892

[11] Ranmuthugala, G., Plumb, J., Cunningham, F., Georgiou, A., Westbrook, J., and Braithwaite, J. How and why are communities of practice established in the healthcare sector? A systematic review. BMC Health Services Research. 2011. PMid:21999305 http://dx.doi.org/10.1186/1472-6963-11-273

[12] Cassidy, L. Online communities of practice to support collaborative mental health practice in rural areas. Issues in Mental Health Nursing. 2011; (32): 98-107. PMid:21247275 http://dx.doi.org/10.3109/01612840.2010.535648

[13] Curran, J. Bridging the gap: Knowledge sharing in a virtual community of emergency practice. Evaluation \& the Health Professions. 2005; 3(23): 314-327.

[14] Lewis, L.A., Koston, Z., Quartley, M. \& Adsit, J. Virtual communities of practice: Bridging research and practice using Web 2.0. Journal of Educational Technology Systems. 2011; 39(2): 155-161. http://dx.doi.org/10.2190/ET.39.2.e 
[15] Wenger, E. Communities of practice and social learning systems: the career of a concept. In Blackmore, C. (Editor) Social Learning Systems and communities of practice. Springer Verlag and the Open University; 2010. http://dx.doi.org/10.1007/978-1-84996-133-2_11

[16] Kaas, M. Teaching in a technology-enhanced and web connected world. Journal of the American Psychiatric Nurses Association. 2010; 16(2): 114-115. PMid:21659269 http://dx.doi.org/10.1177/1078390310365163

[17] Benner, P. From novice to expert. The American Journal of Nursing. 1982; 82(3): 402-407. PMid:6917683

[18] Yalom, I. D. \& Leszcz, M. Theory and Practice of Group Psychotherapy, 5th edition, Basic Books, New York; 2005.

[19] Stein, K. A pressing question: Is there a place for psychotherapy in PMHNP practice? Journal of the American Psychiatric Nurses Association. 2012; 18: 324. PMid:23342398 http://dx.doi.org/10.1177/1078390312469183 